\title{
INTRODUCCIÓN: UN NUEVO ESPACIO EUROPEO
}

\author{
Juan Ignacio PLAZA GUTIÉRREZ \\ Universidad de Salamanca
}

Desde la dirección de la revista Polígonos que inicia ahora -plena de incertidumbre pero cargada de esfuerzo e ilusión- esta su segunda época, se ha querido que su presentación, el comienzo de esta nueva etapa, se llevara a efecto con la edición de un número monográfico centrado en el nuevo espacio europeo. A tal objetivo se han querido encaminar los trabajos que, en número de ocho, componen este volumen.

Cerrado ya casi el primer lustro del nuevo siglo parece, sin embargo, que en la literatura científica sobre estos temas las expresiones "nueva Europa", el "nuevo continente", el "nuevo espacio europeo", la "Europa del nuevo siglo" u otras de significados similares hayan empezado a producir un cierto hartazgo que, todo sea dicho, es más que nada semántico. Ahora bien, por muy manidas que resulten todas estas expresiones, no podemos dejar de constatar que la Europa del siglo XXI se está construyendo sobre unos apoyos institucionales, económicos, sociales, etc. y a partir de procesos de distinto orden que ya empezaron a manifestarse con cierta intensidad en la última década del siglo XX.

Tiene la ventaja, además, todo este cúmulo de aportaciones que integran el presente número que están presididas por la interdisciplinariedad, pues firman los trabajos profesionales que, preocupados todos ellos en su quehacer docente e investigador sobre Europa, proceden de diversas áreas y campos de investigación: la ciencia política, la geografía, la historia, las relaciones internacionales,...Lo cual es enormemente enriquecedor, por cuanto amplía la perspectiva y dimensiones del estudio que debe hacerse sobre el territorio europeo, sus dinamismos, sus problemas, sus perspectivas de evolución, etc.

Pero conviene, asimismo, que subrayemos algunos matices u orientaciones que nos parece oportuno destacar tanto en relación al tema general que aglutina todas las contribuciones que aquí se recogen, como al propio perfil y a la misma estructura del continente europeo. Al hablar del nuevo espacio europeo se ha querido, quizá, poner el acento en una de las partes (cierto que de gran peso) pero no en el todo, pues se piensa en la Unión Europea ampliada (de la que se trazan sus perfiles más básicos y se analiza su proyección espacial en el texto firmado por Juan Ignacio Plaza), en los nuevos miembros que ensanchan y agrandan las fronteras políticas y geográficas del espacio comunitario hasta elevar a 25 el número de sus actuales socios. Tampoco es para menos, pues la "ar- 
quitectura institucional" sobre la que se ha levantado la ampliación del edificio, magníficamente analizada en el artículo de Antonio Moreno Juste, ha resultado ser, con todos sus defectos, una obra de gran envergadura merecedora, cuando menos, de conocerse con cierta precisión (en su trasfondo se adivinan, no obstante, una auténtica "geografía del poder" y el lado más ambicioso por el control de los resortes de la nueva Europa).

Y apenas ha transcurrido medio año desde que el 1 de mayo de 2004 se produjera tal acontecimiento, ya se han retomado nuevamente con intensidad los debates sobre la futura y posible adhesión de Turquía, discusión preñada de sesgos, dudas y objeciones y que ha suscitado recelos en algunas formaciones políticas, en ciertos gobiernos y en no pocos ciudadanos. Junto a todo ello, entre la recién estrenada Unión Europea a 25 y la posible apertura de negociaciones con Turquía, quedan relegados como "convidados de piedra" Rumanía y Bulgaria, los dos próximos estados que, antes que Turquía, muy probablemente se integren en la Unión en el año 2007. Precisamente, el estudio de la evolución, de las perspectivas y de las transformaciones de esta región "bajodanubiana" es el objeto central del artículo de Silvia Marcu.

Sin embargo, la aparente distorsión que pudiese crearse en este volumen con la interpretación del todo desde una de sus partes queda anulada, a nuestro modesto entender, con los dos trabajos con que se abre este número, donde los interrogantes formulados por Carlos Taibo Arias y los conceptos y representaciones expuestos por Francesc López Palomeque respecto al nuevo mapa de Europa, responden a lo que han de ser los fundamentos sobre los que interpretar correctamente y en su dimensión más ampliamente continental el territorio europeo.

Precisamente en ese territorio y entendido a esta escala se suceden y tienen representación otras políticas, problemas diversos y conflictos que se siguen reproduciendo. A todo ello dan cabida y perfecta respuesta los artículos restantes. Sergio Caramelo profundiza con rigor en la trascendencia que alcanzan las estrategias de ordenación espacial en Europa abordadas desde una dimensión escalar transnacional, marco más coherente con lo que deben ser acciones de integración y cooperación territorial. Acciones que tienden, en última instancia, a conseguir un territorio más y mejor articulado, más coherentemente estructurado y vertebrado, contextos todos ellos investigados con sobrada solidez en el artículo que firma David Ramos Pérez, donde las redes transeuropeas de transporte ocupan un lugar central y esencial. Pero un territorio que, pese a su mayor cohesión espacial, se extiende en algunos de sus confines por márgenes donde está presente la inestabilidad y en los que se siguen recrudeciendo enfrentamientos y conflictos geopolíticos y fronterizos, tal y como se recoge en las páginas escritas por Nora Sainz Gsell con las que se cierra este volumen. 
Es éste, en suma, un nuevo producto que nace de la interdisciplinariedad "académica" para converger en el estudio de una realidad continental cambiante como la que representa la Europa del siglo XXI. En sus páginas quedan formuladas y recogidas reflexiones, premisas y observaciones que bien pueden servir de guía de análisis útil para todos aquéllos que, desde distintos campos científicos, pretendan adentrarse en el estudio y conocimiento de los perfiles tan plurales y las transformaciones de nuestro viejo continente. 